\title{
Nanostructured Arrays Formed by Finely Focused Ion Beams
}

\author{
R. A. Zuhr, J. D. Budai, A. Meldrum, R. J. Warmack, and C. W. White \\ Oak Ridge National Laboratory, Oak Ridge, TN
}

P. G. Datsos and K. A. Thomas

The Oak Ridge Y-12 Plant, Oak Ridge, TN

L. C. Feldman

Vanderbilt University, Nashville, TN

M. Strobel and K.-H Heinig

Research Center Rossendorf

Dresden, Germany

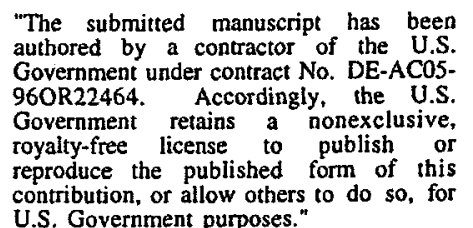

contribution, or allow others to do so, for

U.S. Government purposes.

\author{
Prepared by the \\ Oak Ridge National Laboratory \\ Oak Ridge, Tennessee 37831 \\ managed by \\ LOCKHEED MARTIN ENERGY RESEARCH CORP. \\ for the \\ U.S. DEPARTMENT OF ENERGY \\ under contract DE-AC05-96OR22464
}

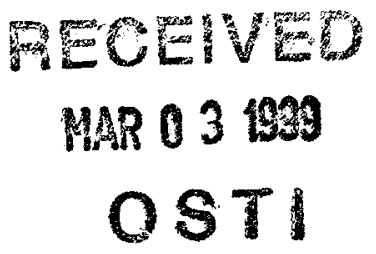

January 1999 


\section{DISCLAIMER}

This report was prepared as an account of work sponsored by an agency of the United States Government. Neither the United States Government nor any agency thereof, nor any of their employees, make any warranty, express or implied, or assumes any legal liability or responsibility for the accuracy, completeness, or usefulness of any information, apparatus, product, or process disclosed, or represents that its use would not infringe privately owned rights. Reference herein to any specific commercial product, process, or service by trade name, trademark, manufacturer, or otherwise does not necessarily constitute or imply its endorsement, recommendation, or favoring by the United States Government or any agency thereof. The views and opinions of authors expressed herein do not necessarily state or reflect those of the United States Government or any agency thereof. 


\section{DISCLAIMER}

Portions of this document may be illegible in electronic image products. Images are produced from the best available original document. 


\title{
NANOSTRUCTURED ARRAYS FORMED \\ BY FINELY FOCUSED ION BEAMS
}

\author{
R. A. Zuhr*, J. D. Budai*, P. G. Datskos*, A. Meldrum*, K. A. Thomas*, R. J. Warmack, C. W. \\ White*, L. C. Feldman $* * *$, M. Strobel ${ }^{* * *}$, and K.-H. Heinig*** \\ * Oak Ridge National Laboratory, Oak Ridge, TN 37831 \\ ** Vanderbilt University, Nashville, TN 37235 \\ *** Research Center Rossendorf, D-01314 Dresden, Germany
}

\section{ABSTRACT}

Amorphous, polycrystalline, and single crystal nanometer dimension particles can be formed in a variety of substrates by ion implantation and subsequent annealing. Such composite colloidal materials exhibit unique optical properties that could be useful in optical devices, switches, and waveguides. However colloids formed by blanket implantation are not uniform in size due to the nonuniform density of the implant, resulting in diminution of the size dependent optical properties. The object of the present work is to form more uniform size particles arranged in a 2-dimensional lattice by using a finely focused ion beam to implant identical ion doses only into nanometer size regions located at each point of a rectangular lattice. Initial work is being done with a $30 \mathrm{keV} \mathrm{Ga}$ beam implanted into $\mathrm{Si}$. Results of particle formation as a function of implant conditions as analyzed by Rutherford backscattering, $\mathrm{x}$-ray analysis, atomic force microscopy, and both scanning and transmission electron microscopy will be presented and discussed.

\section{INTRODUCTION}

It has been shown that amorphous, polycrystalline, and single crystal nanoparticles can be formed in a variety of substrates by ion implantation under prescribed conditions combined with subsequent thermal annealing [1,2,3]. Typical sizes of these particles range from a few nanometers to several hundred nanometers in diameter. They may be metals or semiconductors and can be made of either single or multiple elements, including compound semiconductors, by using sequential implantation techniques. These composite materials frequently exhibit unique optical properties and may find applications in optical devices. One problem of composite materials formed in this way is that the particle size is generally not uniform. In addition, the particles are randomly distributed throughout the implanted region. The purpose of this work is to make uniformly spaced lattices of colloidal particles of more uniform size by using a finely focused ion beam (FEI, FIB200) to implant ions only into a microscopic region (typically $60 \mathrm{~nm}$ diameter) at each point of a two-dimensional array. Simulations using a kinetic lattice Monte Carlo code indicate that such localized implants should form a localized distribution of colloids that, under proper conditions, may Ostwald ripen into a single large colloid at each lattice site [4]. Under these ideal circumstances the colloids formed would be of nearly uniform size because of the identical particle dose implanted at each spot, and in addition they would be uniformly arranged on a two-dimensional lattice. Such a composite would exhibit greatly enhanced optical characteristics.

\section{EXPERIMENT}

Bulk implants of $\mathrm{Ga}$ and $\mathrm{As}$ into $\mathrm{Si}(100)$ at energies of 35 to $160 \mathrm{keV}$ were used to study ion retention vs. dose and GaAs formation. They were made on an Extrion 200-1000 ion 
implantation accelerator at different doses and substrate temperatures in order to understand the behavior of $\mathrm{Ga}$ and As during the low energy implantation which is typical of focused ion beam (FIB) formation of patterned samples. The FIB samples themselves were implanted at $30 \mathrm{keV}$ and room temperature for a variety of different doses, dose rates, beam diameters, and spot patterns using an FEI FIB-2000 focused ion beam system. Substrate temperatures were not controlled during FIB processing.

A number of techniques were employed to study the completed FIB patterned samples. Rutherford backscattering (RBS) using He-4 at $2.3 \mathrm{MeV}$ and a scattering angle of 160 degrees was used to determine the absolute amounts of $\mathrm{Ga}$ retained in the samples after processing. Scanning electron microscopy (SEM) on a JEOL 840 operating at $10 \mathrm{keV}$ was used to observe the implanted pattern as well as the size and shape of the individual dots. Atomic Force Microscopy (AFM) with a digital Instruments Nanoscope III was effective in determining the geometry of the individual implanted dots, including the depth of holes and the height of raised dots, as well as the uniformity of the over all pattern. Low resolution TEM images were taken on a Philips EM400 operating at $100 \mathrm{keV}$, while high resolution images and EDS spectra were made on a Philips CM200 at $200 \mathrm{keV}$.

\section{RESULTS AND DISCUSSION}

\section{Saturation Concentration}

Since the FIB was limited to $30 \mathrm{keV}$, it was necessary to determine the sputtering coefficient for $30 \mathrm{keV} \mathrm{Ga}$ and, as a result, the saturation concentration of $\mathrm{Ga}$ that could be implanted at this energy. Book values for the sputter coefficient ranged around 2 [5]. We measured the retained saturation amount of $\mathrm{Ga}$ directly as a function of incident fluence for $\mathrm{Ga}$ on $\mathrm{Si}$. These results are shown in Fig. 1, which includes values at different substrate temperatures, as well as values for As at the same energy, and a retention curve calculated with the analytical code Profile [6]. In order to fit the experimental $\mathrm{Ga}$ data at liquid nitrogen

35 keV Ga Retention in Si

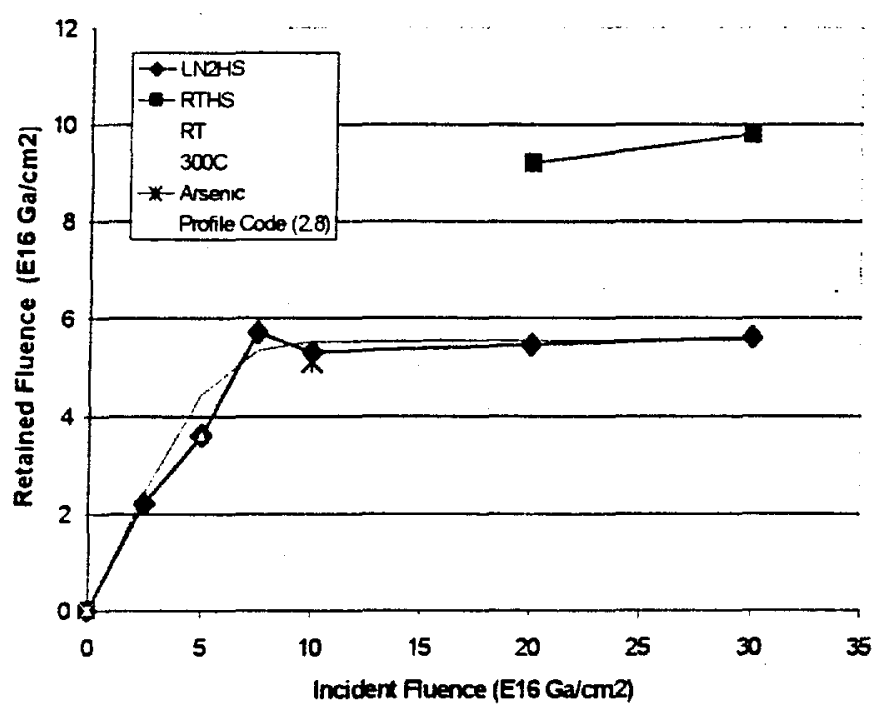
temperatures, a sputtering coefficient of 2.8 was required in Profile. This is close to the tabulated value assumed by Profile (3.1), and is the value that will be used in our discussions. Note that above room temperature, very little of the incident $\mathrm{Ga}$ is retained, due to evaporation from the surface, while at room temperature an interesting phenomenon occurs. It appears that significantly more Ga can be retained at room temperature than at $\mathrm{LN}_{2}$. More careful

Fig. I Retained vs. incident fluence for $35 \mathrm{keV}$ Ga and As on Si measured by RBS at liquid nitrogen. room. and $300 \mathrm{C}$ temperatures. Also shown is a Profile Code calculation for a sputter coefficient of 2.8 . 
investigation of the RBS spectra reveals that this $\mathrm{Ga}$ is concentrated on the surface as evidenced by the shift of the Si edge to lower energy. It appears that for the room temperature samples, the $\mathrm{Ga}$ is sufficiently mobile to form a surface layer of near liquid ( $\mathrm{Ga}$ melts at $29 \mathrm{C}$ ) $\mathrm{Ga}$ globules that is less effectively sputtered by the incident $\mathrm{Ga}$ beam. These globules can be observed optically and are sufficiently "liquid" that they can be blown from the surface with air.

\section{Low Energy Formation of GaAs by Blanket Implants}

The next step was to determine whether GaAs could be formed in Si by ion implantation at energies as low as $30 \mathrm{keV}$ as required by the FIB system. We had previously shown that crystalline GaAs could be formed during ion implantation of the individual elements at both 500 $\mathrm{keV}$ and $150 \mathrm{keV}$ with subsequent thermal annealing," but there were indications that proximity to the surface might result in loss of material rather than compound formation. To study this, $\mathrm{Si}(100)$ samples were implanted sequentially at $35 \mathrm{keV}$ with $5 \times 10^{16}$ each of $\mathrm{Ga}$ and As/cm at $500 \mathrm{C}$, both with As first, and with Ga first. As seen in the RBS spectra of Fig. 2a, most of the $\mathrm{Ga}$ is lost from samples in which the $\mathrm{Ga}$ is implanted first, so studies were concentrated on

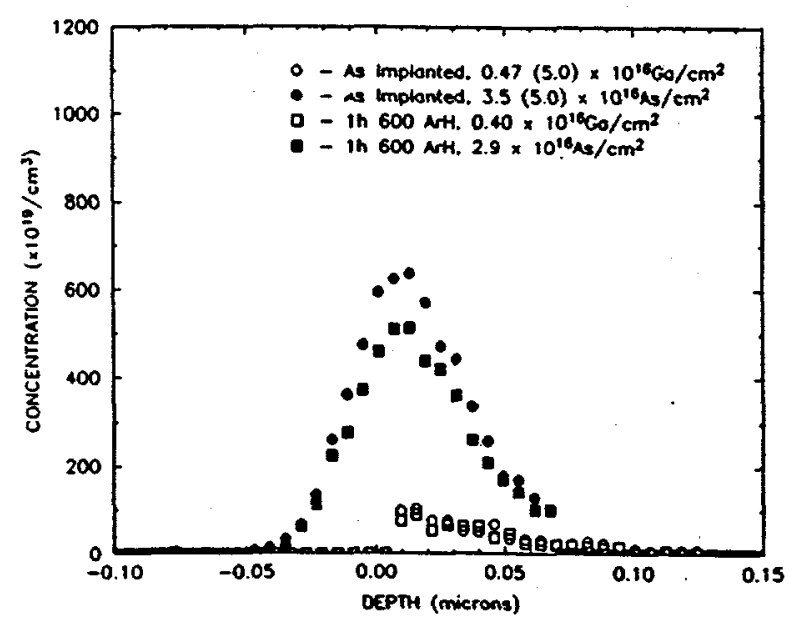

Fig. 2a RBS spectra of $35 \mathrm{keV} \mathrm{Ga}+$ As, $5 \times 10^{16}$ each in $\mathrm{Si}$. as implanted. and anncaled at $600 \mathrm{C}$.

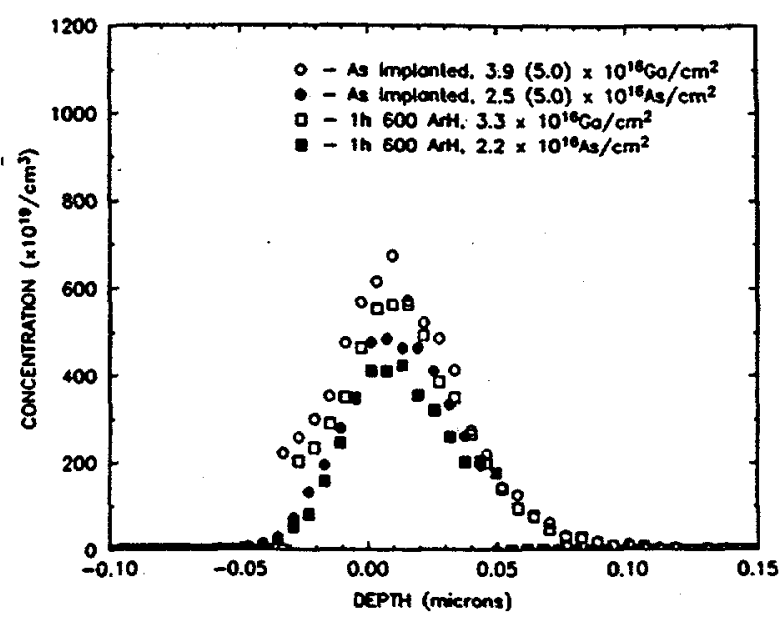

Fig. 2b RBS spectra of $35 \mathrm{keV}$ As $+\mathrm{Ga}, 5 \times 10^{16}$ each in $\mathrm{Si}$. as implanted and annealed at $600 \mathrm{C}$.

samples implanted first with As and subsequently with $\mathrm{Ga}$. Fig. $2 \mathrm{~b}$ indicates that most of the $\mathrm{Ga}$ and As are retained when implanted in this order. Although similar samples implanted at 150 $\mathrm{keV}$ show clear $\mathrm{x}$-ray evidence for the formation of crystalline $\mathrm{GaAs}$, the samples implanted at FIB energies ( $35 \mathrm{keV}$ ) do not. Since formation of GaAs in blanket implanted samples had not been demonstrated, this work on FIB formation of colloids was directed initially toward the formation of elemental Ga particles.

\section{Theoretical Simulation of FIB Implantation}

Kinetic 3D lattice Monte-Carlo simulations are a suitable tool for modeling all basic physical processes of ion beam synthesis of nanocrystals. ${ }^{*}$ For the simulations presented here, a kinetic Ising model is used to incorporate effective $\mathrm{Ga}-\mathrm{Ga}$ interactions within a neutral matrix ( $\mathrm{Ga}-\mathrm{Si}$ interactions can thus be ignored). For a symmetric initial distribution of implanted ions, the code in general predicts aggregation into multiple colloids, with possible Ostwald ripening into single particles at each lattice site. Discussing the present physical parameters, it is obvious that no spherical single precipitates are to be expected. For a nominal beam diameter of $120 \mathrm{~nm}$ (FWHM) and a projected range of about $25 \mathrm{~nm}$, at best a single disk should be formed because of the large lateral to vertical ratio of the effective deposition volume. For simplicity the 


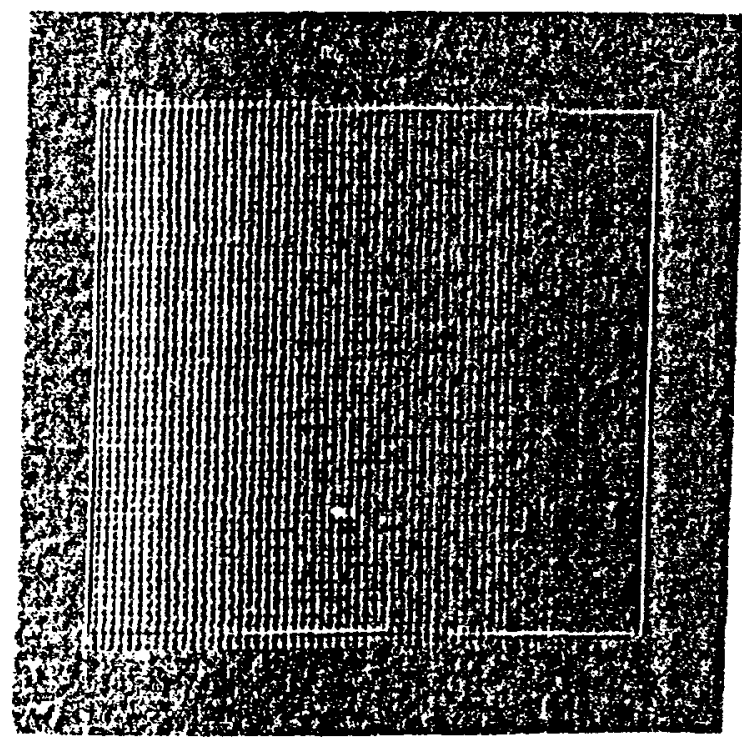

Fig. 3a Optical micrograph of $30 \mathrm{eV} \mathrm{Ga} 64 \times 64$ row pattern on $\mathrm{Si}$. Doses vary from $2 \times 10^{10}$ on the left to $1 \times 10^{6}$ on the right. Square is $1.1 \times 1.1 \mathrm{~mm}$

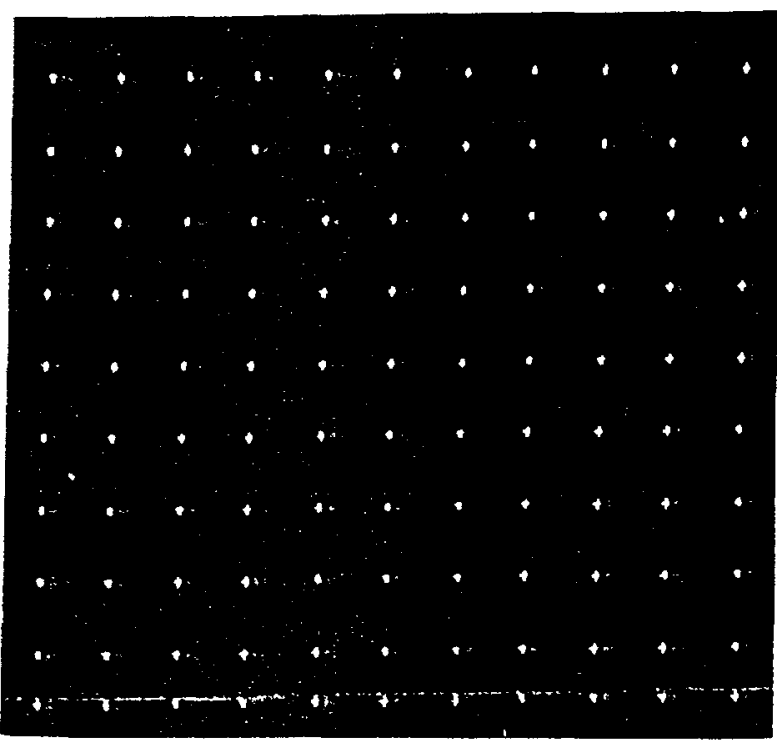

Fig. 3b Optical micrograph of $\mathrm{Ga}$ dots on $\mathrm{Si}$ at 30 $\mathrm{keV}$ and $2 \times 10^{10} \mathrm{Ga} / \mathrm{dot}$ (left side of Fig. 2a) Spacing between dots is 20 microns.

evolution of a single spot was studied starting with an idealized initial configuration matching the assumed Gaussian-like deposited Ga density used in this work. According to the preliminary MC simulation for this set of parameters, formation of a central disk-like nanocrystal is not clear.

\section{Array Formation Using a $30 \mathrm{keV}$ Ga Focused Ion Beam}

The $30 \mathrm{keV} \mathrm{Ga}$ focused ion beam from the FIB-2000 was used to produce arrays of implanted spots at a variety of different doses. Nominal beam diameters of 60 and $120 \mathrm{~nm}$ and currents of 170 and $1000 \mathrm{pA}$, respectively, were used to form $1.1 \mathrm{~mm}$ square patterns of implanted spots in 2-dimensional rectangular lattices on Si substrates. In general, in spite of careful iterative focusing of the ion beam, the observed implant spots are far larger (200 $\mathrm{x}$ in area) and less symmetric than the nominal beam size. Optical micrographs of Fig. 3 show a grid of spots implanted with the $30 \mathrm{keV} 120 \mathrm{~nm}$ beam at spacings of 20 microns between spots. Doses on this sample were increased by a factor of 4 after every 8 rows from a minimum of $1.25 \times 10^{6}$ to $2.05 \times 10^{10} \mathrm{Ga} /$ spot over the 64 row grid, so that a wide range of incident fluences

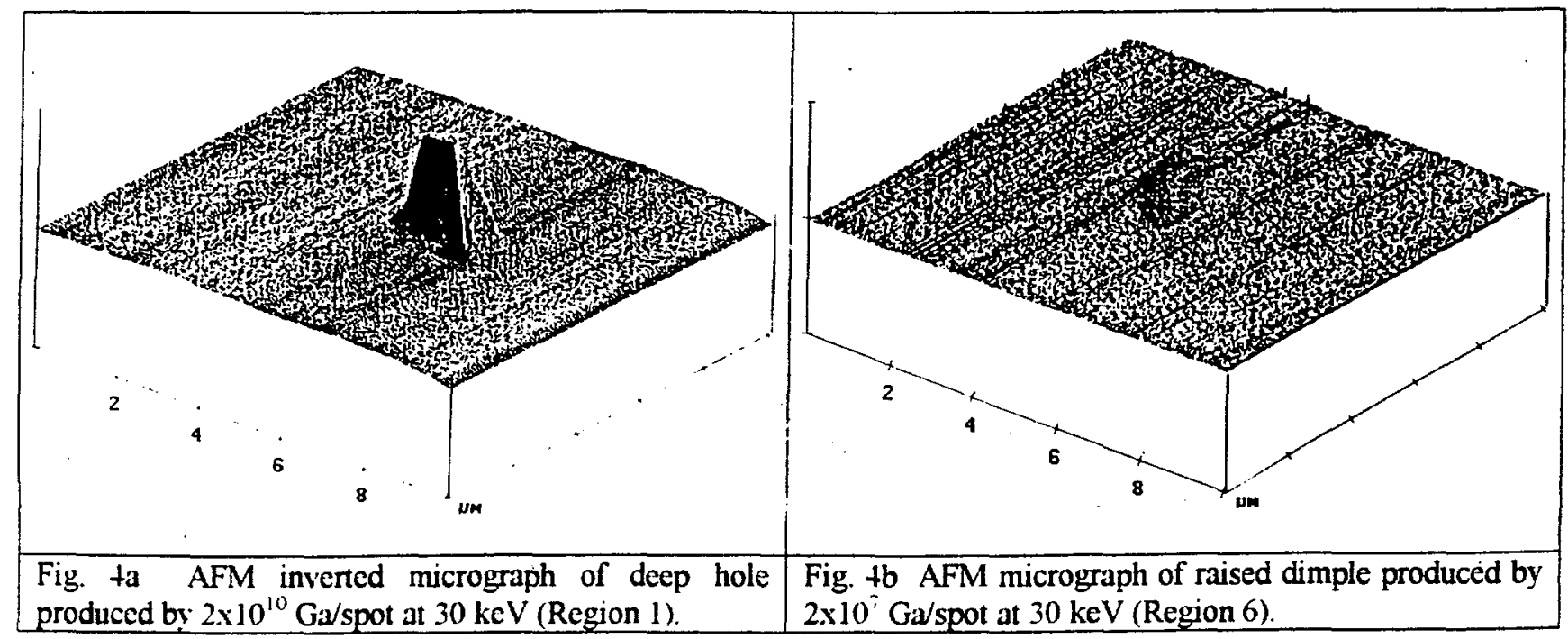




\begin{tabular}{|c|c|c|c|}
\hline Region & lons/Spot & $\begin{array}{l}\text { Area } \\
\mathrm{cm} 2\end{array}$ & $\begin{array}{c}\text { Dose } \\
\text { lons/cm2 }\end{array}$ \\
\hline 1 & $2.05 E+10$ & 2.85E-08 & 7.18E+17 Deep Hole (2 micron) \\
\hline 2 & $5.12 E+09$ & & Deep Hole \\
\hline 3 & $1.28 E+09$ & $1.24 E-08$ & 1.03E+17 Hole \\
\hline 4 & $3.20 E+08$ & & Hole \\
\hline 5 & $8.00 E+07$ & 1.12E-08 & 7.14E+15 Dimple with Hole \\
\hline 6 & $2.00 E+07$ & & Dimple \\
\hline 7 & 5.00E+06 & & Smeared \\
\hline 8 & $1.25 E+06$ & & No Spots \\
\hline
\end{tabular}

would be present. The purpose of this sample was to determine, in light of the disparity between nominal and observed spot sizes, the most effective dose per area for colloid formation. The results in terms of ions $/ \mathrm{cm}^{2}$ of observed spot area and surface topography as measured by AFM are shown in table I. As shown in Fig. 4, the higher doses produce deep holes, the lightest doses leave the substrate unaffected, and intermediate doses produce a slight rise in the implanted region. The raised areas at moderate doses are presumed to be due to incorporation of $\mathrm{Ga}$ along with the conversion of the area from single crystai $\mathrm{Si}$ to the less dense amorphous phase. The high aspect ratio holes at high doses clearly represent a poor geometry from which to form the desired single uniform size colloid at each lattice site, while the lowest doses provide insufficient $\mathrm{Ga}$ to produce a colloid. Therefore, the moderate dose regions, such as region 5 in the table, with a dose of 7E15 ions $/ \mathrm{cm}^{2}$, should be most interesting.

The presence of $\mathrm{Ga}$ in the implanted dots has been observed by several techniques. Confirmation of the retention of $\mathrm{Ga}$ has been shown by RBS to be $1.1 \times 10^{14} \mathrm{Ga} / \mathrm{cm}^{2}$ over the entire pattern, which is in agreement with the amount expected to be retained after sputtering. The qualitative presence of $\mathrm{Ga}$ in each individual lattice spot has been demonstrated by $\mathrm{x}$-ray analysis by scanning the pattern with a 1.5 micron white $x$-ray beam and observing the resulting Ga line, which is observed only when the beam is on a spot. Fig. 5 shows a TEM image of a particle of $\mathrm{Ga}$ formed near the edge of an implanted spot taken from region 4 in the table. The particle is about $18 \mathrm{~nm}$ in diameter and can be positively identified as $\mathrm{Ga}$ from the EDS spectrum in the figure. Therefore small Ga colloids are formed at the lattice points, but uniform single colloids have not yet been observed.

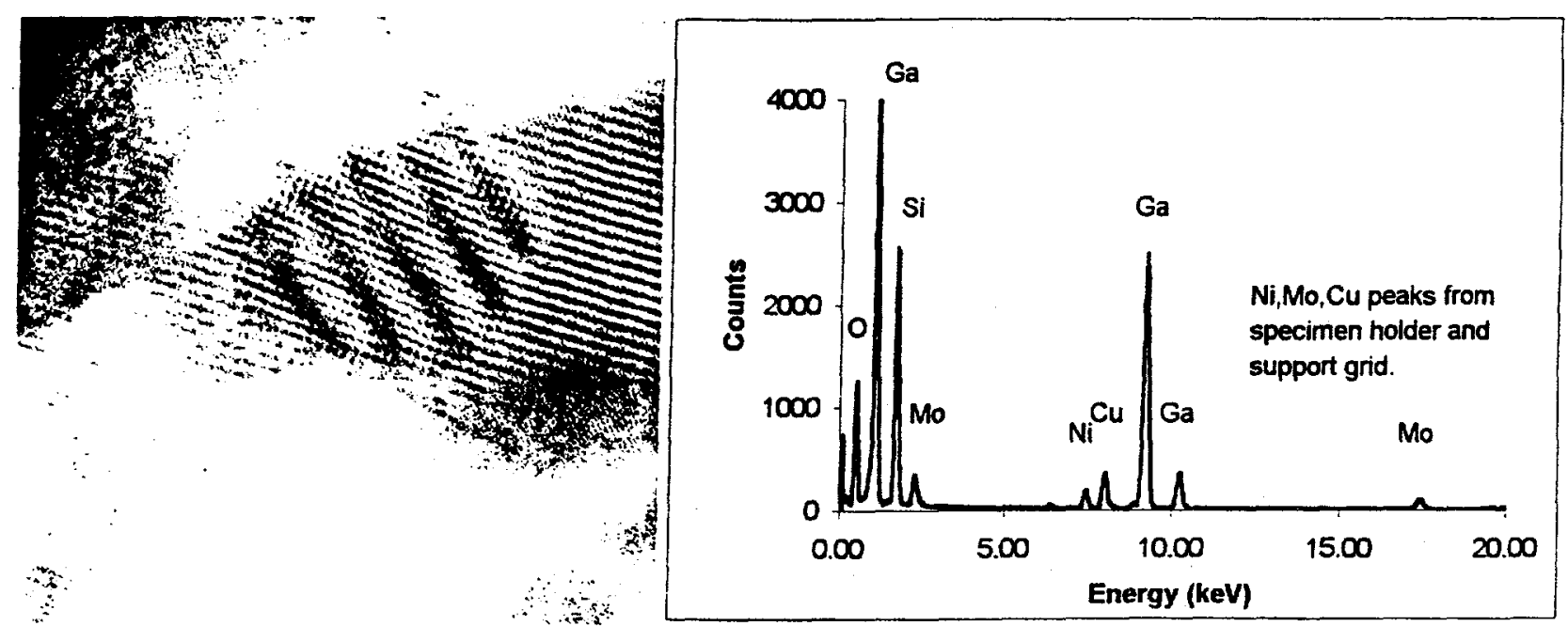

Fig. 5a TEM micrograph showing Moire fringes of Ga particle formed by $3.2 \times 10^{8} 30 \mathrm{keV} \mathrm{Ga} /$ spot (Region 4).

Fig. 5b EDS spectrum from particle in 5a indicating that the particle is $\mathrm{Ga}$. 


\section{CONCLUSION}

It has been demonstrated that a 2-dimensional lattice of $\mathrm{Ga}$ dots can be written on a $\mathrm{Si}$ substrate using a programmed finely focused ion beam at $30 \mathrm{keV}$. Aggregation of the roughly Gaussian implanted profile into a single particle at each of the lattice sites has not been demonstrated, but it is clear that $\mathrm{Ga}$ is retained in the substrate and does form small crystalline colloids. The dose and energy, and thus the depth, of the implanted ions appears to be critical in the formation of larger single particles, since the $\mathrm{Ga}$ ions must be implanted into a relatively undisturbed region of the substrate in order to form a single colloid. High doses drill holes into the substrate surface (See Fig. 5), leaving Ga spread around the wall and bottom of the hole, which produces an unsuitable geometry from which to diffuse the $\mathrm{Ga}$ into a single particle. Therefore the fluence should be limited to a value which leaves the implanted regions of the surface relatively flat. Based on the current work, such doses are on the order of $1 \times 10^{16}$ ions $/ \mathrm{cm}^{2}$. In addition, for the formation of compound semiconductors, the individual elements, $\mathrm{Ga}$ and As, must buried deep enough beneath the surface so that they do not escape from the surface during annealing or even during the implant itself. To date, using a blanket implant of $35 \mathrm{keV}$ As followed by localized $30 \mathrm{keV}$ FIB implants of $\mathrm{Ga}$, we have not been able to produce GaAs quantum dots, although we have demonstrated that GaAs nanoparticles can be formed by blanket sequential implantation of the individual elements at $150 \mathrm{keV}$. Several techniques are proposed to produce such compound semiconductor quantum dots by the FIB process in the future, including higher energy ( $150 \mathrm{keV}) \mathrm{FIB}$, and capping of the pattern with $\mathrm{SiO}_{2}$ prior to high temperature annealing to form the GaAs. These ideas are currently undergoing further study.

\section{ACKNOWLEDGMENT}

The authors are indebted to Chuck Egert, who recently passed away, for arranging this collaboration. Oak Ridge National Laboratory is managed by Lockheed Martin Energy Research Corp. for the U. S. Department of Energy under contract number DE-AC05-96OR22464.

\section{REFERENCES}

1. G. W. Arnold, J. A. Borders, J. Appl. Phys. 489, p. 1488 (1977).

2. C. W. White, et al., "Encapsulated Nanocrystals and Quantum Dots Formed by Ion Beam Synthesis," Nucl. Instrum. Meth. Phys. Res. B 127/128, p. 545 (1997).

3. R. A. Zuhr and R. H. Magruder, III, "Optical Properties of Multi-Component Metallic Nanoclusters Formed in Silica by Sequential Ion Implantation," invited paper, Journal of the Surface Science Society of Japan 18, \#5, p. 269 (1997).

4. M. Strobel, K.-H. Heinig, W. Moller, A. Meldrum, D. S. Zhou, C. W. White, and R. A. Zuhr, "Ion Beam Synthesis of Gold Nanoclusters in SiO2: Computer Simulations Versus Experiments," Nucl. Instrum. Meth. Phys. Res. B, to be published.

5. Sputtering by Particle Bombardment, ed. by R. Behrisch, Springer-Verlag, Berlin, 1981, p. 169 .

6. The Profile Code is a product of Implant Sciences Corporation, Wakefield, MA. 